\title{
Cytokines, GM-CSF and IFN $\gamma$ administered by priming and post-chemotherapy cycling in recurrent ovarian cancer patients receiving carboplatin
}

\author{
Sachin M Apte ${ }^{1}$, Saroj Vadhan-Raj ${ }^{2}$, Lorenzo Cohen ${ }^{3}$, Roland L Bassett ${ }^{4}$, \\ Ilyssa O Gordon ${ }^{1}$, Charles F Levenback ${ }^{1}$, Pedro T Ramirez ${ }^{1}$, \\ Stacie T Gallardo ${ }^{1}$, Rebecca S Patenia ${ }^{1}$, Michael E Garcia ${ }^{1}$, Revathy B Iyer ${ }^{5}$ and \\ Ralph S Freedman*1
}

Address: ${ }^{1}$ Department of Gynecologic Oncology, The University of Texas M.D. Anderson Cancer Center, Houston, Texas, USA, ${ }^{2}$ Department of Bioimmunotherapy, The University of Texas M.D. Anderson Cancer Center, Houston, Texas, USA, ${ }^{3}$ Department of Behavioral Science, The University of Texas M.D. Anderson Cancer Center, Houston, Texas, USA, ${ }^{4}$ Department of Biostatistics, The University of Texas M.D. Anderson Cancer Center, Houston, Texas, USA and ${ }^{5}$ Department of Diagnostic Radiology, The University of Texas M. D. Anderson Cancer Center, Houston, Texas, USA

Email: Sachin M Apte - aptesm@moffitt.usf.edu; Saroj Vadhan-Raj - svadhanr@mdanderson.org; Lorenzo Cohen - lcohen@mdanderson.org; Roland L Bassett - rlbasset@mdanderson.org; Ilyssa O Gordon - Ilyssa.a.okrent@uth.tmc.edu;

Charles F Levenback - clevenba@mdanderson.org; Pedro T Ramirez - peramir@mdanderson.org; Stacie T Gallardo - stemplin@mdanderson.org; Rebecca S Patenia - rpatenia@mdanderson.org; Michael E Garcia - mgarcia@mdanderson.org; Revathy B Iyer - riyer@mdanderson.org;

Ralph S Freedman* - rfreedma@mdanderson.org

* Corresponding author

Published: 07 April 2006

Journal of Translational Medicine2006, 4:16 doi:10.1 186/1479-5876-4-16
Received: 27 January 2006

Accepted: 07 April 2006

This article is available from: http://www.translational-medicine.com/content/4/I/16

(c) 2006Apte et al; licensee BioMed Central Ltd.

This is an Open Access article distributed under the terms of the Creative Commons Attribution License (http://creativecommons.org/licenses/by/2.0), which permits unrestricted use, distribution, and reproduction in any medium, provided the original work is properly cited.

\begin{abstract}
Background: Monocyte/macrophages (MO/MA), a polymorphic population of innate immune cells, have the potential to mediate antitumor effects, and may also contribute to protumor effects. A priming and post-chemotherapy schedule of the myeloid cell mobilizing and immune stimulatory growth factor, granulocyte monocyte stimulating factor (GM-CSF, Leukine $\left.{ }^{\circledR}\right)$ and the MO/MA activating cytokine recombinant interferon gamma lb ( $\mathrm{rlFN}-\gamma \mathrm{lb}$, Actimmune ${ }^{\circledR}$ ) has been developed. The pre- and post-chemotherapy design is based upon known in vivo kinetics and immune modulatory effects of these molecules. Carboplatin (Paraplatin ${ }^{\circledR}$ ) was selected as the cornerstone of treatment of epithelial ovarian cancer (EOC).

Methods: We studied hematopoietic and immunologic effects of GM-CSF and rIFN- $\gamma$ lb before and after carboplatin in patients with recurrent EOC. Potentially chemotherapy-sensitive patients with recurrent measurable tumors received subcutaneous GM-CSF (starting at $400 \mu \mathrm{g} / \mathrm{day}$ ) for 7 days plus subcutaneous rIFN- $\gamma \mathrm{lb}(\mathrm{I} 00 \mu \mathrm{g})$ on days 5 and 7 , before and after intravenous carboplatin (area under the curve of 5). We performed standard hematologic assessment and monitored monocyte (MO), dendritic cell, major cell subset counts, and antibody-dependent cell-mediated cytotoxicity (ADCC) against a Her2neu+ tumor cell line, as well as selected plasma inflammatory cytokine, chemokine and growth factor levels.
\end{abstract}

Results: Our analysis comprised only the first 3 months of treatment in the initial 25 patients. Relative to pretreatment baseline values, white blood cell, neutrophil, $M O$, and eosinophil counts 
increased ( $P \leq .00 \mathrm{I}$ for each); the proportion of platelets increased 9 days after the second $(P \leq$ $.002)$ and third $(P \leq .04)$ carboplatin treatments; and the number of cells in the activated $M O$ subsets CDI4+HLA-DR+, CD I4+CD64+, and CDI4+CXCR3 ${ }^{+}$increased $(P \leq .04$ for each); plasma levels of the proangiogenic interleukins $I \alpha, 6$, and 8 were lower $(P \leq .03$ for each); $M-C S F$, a product of activated MO/MA, was increased on day $9(P=.007)$; and GM-CSF was increased in plasma after GM-CSF administration $(P \leq .04)$. Quality of life measurements were reduced during the GM-CSF/IFN- $\gamma$ Ib cycle while recovering at pre-chemotherapy baseline for FACT-G scores only.

Conclusion: A novel regimen of GM-CSF plus IFN- $\gamma$ lb administered to $25 \mathrm{EOC}$ patients receiving carboplatin increased myeloid cells, platelets and total activated $\mathrm{MO}$ populations during the initial 3 months; however, ADCC responses were not consistently enhanced during this period.

\section{Introduction}

In 2005 there will be an estimated 22,200 new cases of epithelial ovarian cancer (EOC) and 16,210 deaths from it in the United States, where EOC is the fifth most common cause of cancer-related death in women [1]. The 5year overall survival rate for patients with distant metastases is $30.9 \%$ [2]. Platinum is the cornerstone of chemotherapy for EOC and, together with paclitaxel, is the most frequently used first-line therapy $[3,4]$. Recurrences after first-line chemotherapy are typically treated with carboplatin, liposomal doxorubicin, a taxane, topotecan, gemcitabine, or etoposide [5], either as single agents or in combination; single agents, including carboplatin, generate a response rate of $15 \%$ to $30 \%$, and response rates are higher after a treatment-free interval of $\geq 6$ months [6]. A $7 \%$ improvement in survival was recently reported for carboplatin plus paclitaxel over "conventional" platinumbased chemotherapy for recurrent EOC [7]. It remains unknown, however, whether sequential use of these agents might produce an equivalent or better survival outcome.

Monocytes and macrophages (MO/MAs) are the most common innate cell population in humans. Their role in cancer patients is complex because they may either enhance or impair immunity. Granulocyte-monocyte colony-stimulating factor (GM-CSF) and recombinant interferon gamma $1 \mathrm{~b}$ (IFN- $\gamma 1 \mathrm{~b})$ are commercially available cytokines that can modulate MO/MA activity. GM-CSF can mobilize and mature myeloid cells, including $\mathrm{MO} /$ MAs and dendritic cells (DCs) [8,9], whereas IFN- $\gamma 1 \mathrm{~b}$ is an activator of $\mathrm{MO} / \mathrm{MAs}[10,11]$.

At biologically active doses, GM-CSF increases both neutrophil and MO counts to reach a plateau within 5 to 10 days [12]. When administered after chemotherapy, GMCSF reduces the duration of neutropenia and enhances recovery. Prior studies have also demonstrated that intravenous "priming" with GM-CSF before chemotherapy with anthracycline-based chemotherapy expands the pool of myeloid progenitor cells and induces these cells to become quiescent, which may enhance myeloprotection with shortening the duration of severe neutropenia $[13,14]$.

GM-CSF may also stimulate the immune system by enhancing antitumor effects by either innate or adaptive antitumor immunity $[15,16]$. Thus, GM-CSF induces destruction of tumor cells in vitro by stimulated peripheral blood MOs [17], enhances DC maturation [18,19], and has become an important component of certain vaccine trials. In addition to other applications [20], GM-CSF has shown promising results as an adjuvant in melanoma [15] and in breast cancer [21]. GM-CSF has been combined with other cytokines $(e . g, . r I F N-\alpha$, interleukin 2 [IL$2]$, and IFN- $\gamma 1 \mathrm{~b})$ and provided some treatment effects against metastatic renal tumors and melanoma [22,23]. Optimum dosing and scheduling of these combinations have not been determined. The addition of other cytokines could have either synergistic or antagonistic effects on GM-CSF's leukocytic proliferation and maturational properties. GM-CSF alone can expand and prime MOs destined to migrate to tissues as MAs, but other stimuli may be needed to mature or activate these cells more fully. Such stimuli could be provided by other cytokines, such as IFN- $\gamma$.

We designed a clinical trial of two immunomodulatory cytokines, GM-CSF and IFN- $\gamma 1 \mathrm{~b}$, administered both before and after carboplatin treatment in patients with platinum-sensitive EOC that had recurred. We expected that IFN- $\gamma 1 \mathrm{~b}$ (administered during the latter half of the GM-CSF cycle) would enhance the activation of MO/MAs while GM-CSF would exert its proliferative effects on myeloid progenitor cells, minimizing any possible antiproliferative effects from the IFN- $\gamma 1 \mathrm{~b}$. Here we report the hematopoietic and myeloid immune cell effects during the first three courses of a chemoimmunotherapy regimen that consisted of GM-CSF and IFN- $\gamma 1 \mathrm{~b}$ priming, carboplatin, and post-carboplatin GM-CSF and IFN- $\gamma 1 \mathrm{~b}$. Detailed analysis of the response and toxicity of the ongoing phase II trial will be reported after the trial's completion. 


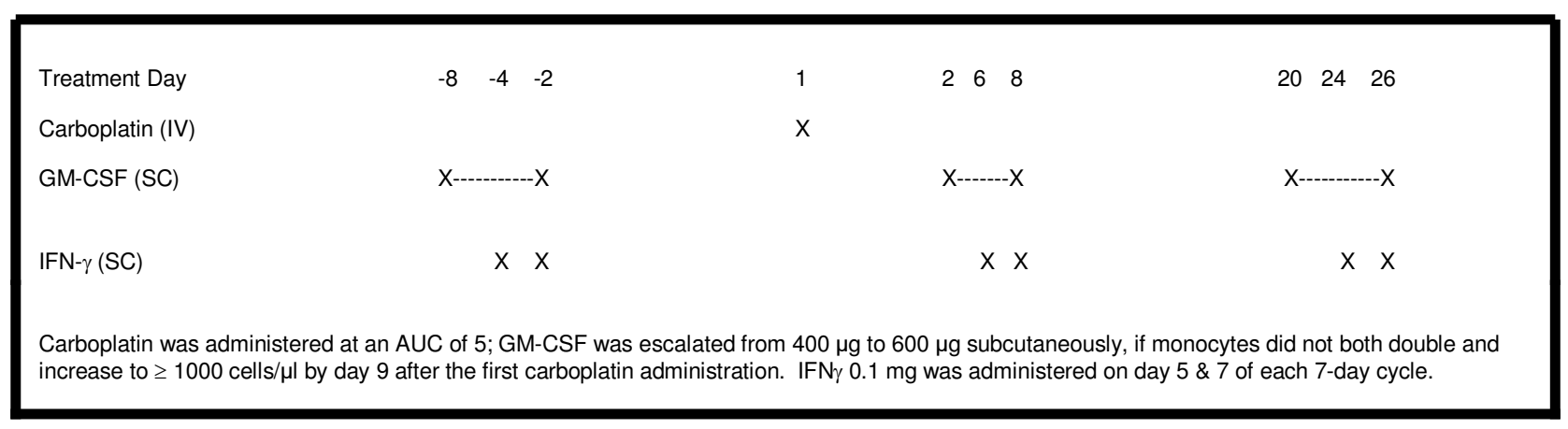

\section{Figure I}

Treatment Schema. Schematic of 28-day cycle for the administration of GM-CSF, rIFN- $\gamma$ Ib, and carboplatin.

\section{Patients and methods Patient population}

Patients eligible for inclusion in the study had Müllerian carcinoma (primary epithelial ovarian, primary peritoneal, or fallopian tube) that had initially responded to platinum-based chemotherapy but recurred after a treatment-free interval of $\geq 6$ months; these tumors were considered "potentially platinum sensitive." Patients were also required to have radiographically or clinically measurable disease and CA-125 determinations. Adequate hematologic, renal, and hepatic function was required as defined by: absolute neutrophil count $\geq 1,500$ cells $/ \mu \mathrm{L}$, platelet count $\geq 100,000$ cells $/ \mu \mathrm{L}$, serum creatinine $\leq 1.5$ $\mathrm{mg} / \mathrm{dL}$, serum bilirubin $\leq 1.5 \mathrm{mg} / \mathrm{dL}$, and aspartate transaminase $\leq 2.5 \times$ normal. A Zubrod performance status score of $\leq 2$ was also required. Patients could not have received more than two prior chemotherapy regimens (first-line platinum and platinum re-induction were counted as one regimen). Other exclusion criteria included prior immunotherapy, abdominal radiotherapy, active heart or autoimmune disease, inflammatory bowel disease, brain metastases, serum albumin $\leq 3 \mathrm{~g} / \mathrm{dL}$, or known hypersensitivity to platinum agents. All patients provided informed consent for participation in this IRB approved study.

\section{Cytokines}

GM-CSF (Leukine ${ }^{\circledast}$, specific activity $5.6 \times 10^{6} \mathrm{IU} / \mathrm{mg}$; Berlex Labs, Seattle, WA) was provided in vials containing either 250 or $500 \mu \mathrm{g}$ of the lyophilized powder and $40 \mathrm{mg}$ of mannitol, $10 \mathrm{mg}$ of sucrose, and $1.2 \mathrm{mg}$ of tromethamine. The cytokine was reconstituted with $1.0 \mathrm{~mL}$ of either bacteriostatic water or sterile water at room temperature.

IFN- $\gamma 1 \mathrm{~b}$ (Actimmune ${ }^{\circledast}$, specific activity $20 \times 10^{6} \mathrm{IU} / \mathrm{mg}$ noncovalent form of dimeric protein; InterMune, Bris- bane, CA) was provided in 0.5-mL vials containing $100 \mu \mathrm{g}$ of IFN- $\gamma 1 \mathrm{~b}, 20 \mathrm{mg}$ of mannitol, $0.36 \mathrm{mg}$ of sodium succinate, and $0.05 \mathrm{mg}$ of polysorbate-20. The cytokine was reconstituted in $0.5 \mathrm{~mL}$ of sterile water at room temperature.

\section{Treatment regimen (Figure I)}

For each course of treatment, GM-CSF was administered by subcutaneous injection in two 7-day cycles, one preceding and the other one following a fixed intravenous dose of carboplatin (Paraplatin ${ }^{\circledR}$, Bristol-Myers Squibb, New York, NY) at an area under the curve of 5 (Calvert Formula). Carboplatin was administered 48-60 hours after the last dose of GM-CSF. For the post-chemotherapy cycle, GM-CSF was started within 24-36 hours. For the first and second cycles of GM-CSF, the dose started at 400 $\mu \mathrm{g}$ per day and escalated to $600 \mu \mathrm{g}$ per day if the $\mathrm{MO}$ count did not at least double and reach a level of 1,000 cells/ $\mu \mathrm{L}$. The GM-CSF dose could be reduced by $200 \mu \mathrm{g}$ in response to grade 3 major organ toxicity. IFN- $\gamma 1 \mathrm{~b}$ was administered by subcutaneous injection at a fixed dose of $100 \mu \mathrm{g}$ on the fifth and seventh days of each 7-day cycle of GM-CSF. No dose escalation of IFN- $\gamma 1 \mathrm{~b}$ was permitted.

For subsequent courses, the pre-chemotherapy GM-CSF/ IFN- $\gamma$ cycle was scheduled to start on day 20. For individual patients who had an absolute neutrophil count of $<1,000 / \mu \mathrm{L}$ or a platelet count of $<100,000 / \mu \mathrm{L}$, the subsequent treatment course was delayed until recovery of absolute neutrophil count to $\geq 1,000 / \mu \mathrm{L}$ and platelet count to $\geq 100,000 / \mu \mathrm{L}$. After recovery, the second dose of IFN- $\gamma 1 \mathrm{~b}$ was omitted on each subsequent cycle of GM-CSF in patients who developed significant neutropenia or thrombocytopenia.

Patients who developed grade 3 allergic reactions were treated with appropriate desensitization. Responses were 
determined using modified World Health Organization Response Evaluation Criteria in Solid Tumors (RECIST) [24]. Up to three courses of the chemoimmunotherapy regimen were required for the current assessment of hematologic and immunologic effects.

\section{Hematologic and blood chemistry monitoring}

Before the start of each treatment course (i.e, within 10 days before the first GM-CSF dose), the following were checked for each patient: complete blood count, serum creatinine, blood urea nitrogen, total bilirubin, aspartate transaminase, alanine transaminase, electrolytes $(\mathrm{Na}, \mathrm{K}$, $\mathrm{Cl}$, and $\mathrm{Mg}$ ), carbon dioxide, serum albumin, total protein, glucose, alkaline phosphate, lactate dehydrogenase, and CA-125. A complete blood count was also obtained on days $-4,1,6,9,16,21,25$, and 28 of the first treatment course to monitor the pre and post-chemotherapy GMCSF/IFN- $\gamma$ and on days $1,9,16,21$, and 28 of the second and third treatment courses.

\section{Immunologic monitoring}

In the 12 patients who consented to optional studies, peripheral blood was examined for the number and activation (or maturation) status of MOs and DCS and for in vitro cytotoxicity experiments. Blood specimens were collected on day -8 of the first treatment course before the start of rIFN- $\gamma 1 \mathrm{~b}$ treatment on day -4 , before the start of carboplatin treatment on day 1 , and 9 days after carboplatin treatment. Additional specimens were collected from patients 3 months after the first treatment course was begun. Peripheral blood $(10 \mathrm{ml})$ was collected in ACD (yellow top) vacutainer tubes The blood was centrifuged, the plasma collected, and the mononuclear cells isolated by Ficoll-Hypaque density gradient separation. In addition, for cytotoxicity studies, MOs were obtained from anonymized normal donors through the blood bank as controls.

\section{Flow cytometry}

MOs were identified within mononuclear cell preparations by flow cytometry as CD14bright leukocytes or CD14dim, CD45+ leukocytes. Mononuclear leukocytes were further characterized for coexpression of HLA-DR, CD64, and in some instances CD32 and CD32B. DCs were identified directly in mononuclear cell preparations of blood as lineage-negative, HLA-DR+ leukocytes by using multidimensional flow cytometry $[25,26]$. Additionally, three-color labeling was performed to evaluate the proportion and absolute numbers of $\mathrm{CD} 11 \mathrm{c}^{+}$pre-DC1 cells and CD123+ and pre-DC2 cell subsets [27]. Because the maturation of DCs has been shown to be accompanied by expression of CD83, lineage-negative, HLA-DR+ DCs were also tested for coexpression of this marker. $\mathrm{CD}^{16^{+}}$and CD16-MOs have been shown to give rise to DCs with different phenotypic and functional properties
[28]. Therefore, we also monitored this marker, as well as CD2 (which is also expressed on a subset of MOs with the potential to develop into DCs) [29]. For functional analysis, MOs were isolated from mononuclear cell preparations by negative selection using immunomagnetic cell sorting (Miltenyi Biotech, Bergisch Gladbach, Germany). Staining for the CXCR3+ chemokine receptor was performed on $\mathrm{MO}$ of selected patients using a PE-Cy5 labeled $\mathrm{mAb}$ in conjunction with a PE labeled CD14 mAb.

\section{Monocyte-mediated tumor cell cytotoxicity and Antibody- Dependent Cellular Cytotoxicity (ADCC) assays}

Enriched MOs from EOC patients undergoing treatment were tested for their ability to induce the cytotoxicity of tumor cells directly or in the presence of an antibody capable of mediating ADCC by using a ${ }^{3} \mathrm{H}$-TdR release assay we developed [30,31]. Briefly, washed SKOV3 human ovarian cancer cells, which are Her2neu+, were labeled with ${ }^{3} \mathrm{H}$-labeled thymidine (specific activity of 185 $\mathrm{GBq} / \mathrm{mmol} ; 50 \mu \mathrm{Ci}$ per $1.2 \times 10^{6}$ cells) in $10 \mathrm{~mL}$ of RPMI 1640 medium with heat-inactivated $15 \%$ fetal bovine serum for 18 to 24 hours at $37^{\circ} \mathrm{C}$ in a humidified $5 \% \mathrm{CO}_{2}$ incubator. Target cells were incubated with the humanized IgG1 antibody trastuzumab (Herceptin, Genentech, San Francisco, CA), which recognizes the Her2neu surface antigen, at a concentration of $5 \mu \mathrm{g} / \mathrm{mL}$ for $30 \mathrm{~min}$ at $37^{\circ} \mathrm{C}$ in a shaking water bath. Sensitized target cells were washed once and seeded with $\mathrm{MO} / \mathrm{MAs}$ at an effects-totarget ratio of 20:1 in 96-well U-bottom microtiter plates. Purified MO were isolated from PBMC by negative selection, using a MO Isolation Kit and a MACS separator (Miltenyi Biotec, Auburn, CA) as per manufacturer's instruction. MOs obtained from non-MCSF stimulated buffy coat samples were utilized as controls as previously described [32] were incubated with murine 2B6 monoclonal antibody (kindly provided by MacroGenics, Rockville, $\mathrm{MD}$ ) that recognize $\mathrm{CD} 32 \mathrm{~B}$ at a concentration of 1.5 $\mu \mathrm{g} / \mathrm{mL}$ in $1 \times 10^{6}$ cells for 1 hour. Plates were centrifuged at $1,000 \mathrm{rpm}$ for $1 \mathrm{~min}$ and incubated for 60 to 72 hours at $37^{\circ} \mathrm{C}$ in a humidified $5 \% \mathrm{CO}_{2}$ incubator.

Plates were spun down at $1,000 \mathrm{rpm}$ for $5 \mathrm{~min}$ at $25^{\circ} \mathrm{C}$, and cell-free supernatants were transferred to scintillation vials into which $5 \mathrm{~mL}$ of scintillation fluid was added (Safety Solve; Research Products International, Mount Prospect, IL). ${ }^{3} \mathrm{H}-\mathrm{TdR}$ release from target cells was counted in a WinSpectral liquid scintillation counter $(E G \& G$; Wallac, Turku, Finland) for $1 \mathrm{~min}$. The percent ADCC for MO/ MAs was calculated as (experimental release - spontaneous release $) \div$ (maximum release - spontaneous release) $\times$ 100 , in which release values are in counts per minutes and experimental release is counts from cell-free culture supernatant from $\mathrm{MO} / \mathrm{MAs}$ incubated with labeled tumor cells, spontaneous release is counts from cell-free culture supernatant from labeled tumor cells only, and maximum 
Table I: Patient and Tumor Characteristics and Prior Treatment $(\mathbf{N}=\mathbf{2 5})$

\begin{tabular}{|c|c|}
\hline Characteristic or Treatment & No. of Patients \\
\hline \multicolumn{2}{|l|}{ Zubrod performance status score } \\
\hline 0 & 22 \\
\hline 1 & 1 \\
\hline 2 & 2 \\
\hline \multicolumn{2}{|l|}{ Race } \\
\hline White & 22 \\
\hline Hispanic & 2 \\
\hline Black & I \\
\hline \multicolumn{2}{|l|}{ Primary tumor site } \\
\hline Ovary & 22 \\
\hline Peritoneum & 2 \\
\hline Fallopian tube & 1 \\
\hline \multicolumn{2}{|l|}{ Histologic subtype } \\
\hline Serous & 22 \\
\hline Clear cell & 1 \\
\hline Endometrioid & I \\
\hline Adenocarcinoma & 1 \\
\hline \multicolumn{2}{|l|}{ First-line chemotherapy } \\
\hline Paclitaxel and carboplatin & 23 \\
\hline Paclitaxel and cisplatin & 1 \\
\hline Cisplatin and doxorubicin & I \\
\hline \multicolumn{2}{|l|}{ Prior reinduction chemotherapy } \\
\hline Carboplatin & 4 \\
\hline High dose with bone marrow transplantation & I \\
\hline None & 20 \\
\hline \multicolumn{2}{|l|}{ Prior hormonal treatment } \\
\hline Yes & 10 \\
\hline No & 15 \\
\hline \multicolumn{2}{|l|}{ Pelvic irradiation } \\
\hline Yes & 1 \\
\hline No & 24 \\
\hline
\end{tabular}

release is counts from cell-free culture supernatant from lysed (5\% Triton) labeled tumor cells only.

\section{Plasma cytokine and chemokine measurements}

Patients who consented to optional studies provided samples for measurement of plasma levels of cytokines IL- $1 \alpha$, IL-1 $\beta$, IL-6, IL-10, and TNF- $\alpha$ and the chemokine CXCL8 (IL-8). Plasma samples were taken on days $-8,-4,1$, and 9 of the first course and at 3 months after the first treatment course was begun. We used the Multiplex Bead chemoluminescence assay (Luminex, Austin, TX). The Multiplex Bead Immunoassay is a multiplex assay that uses the Luminex 100 analyzer (Austin, TX) and associated software. Levels of multiple cytokines are measured in small volumes by using fluorescently encoded microspheres labeled with a distinguishable fluorophore that allows the microspheres to be gated to a particular region by the scanner. Antibodies specific for the cytokine or chemokine of interest (Biosource International, Camarillo, CA) are covalently linked to individual beads of a different fluorescent marker, thereby causing the cytokines or chemokine to bind to the specific complementary antibody- coated bead and produce a unique fluorescent signature. The minimum detectable levels using this method are: IL1 $\alpha, 5 \mathrm{pg} / \mathrm{mL} ;$ IL-1 $\beta, 15 \mathrm{pg} / \mathrm{mL}$; IL-6, $3 \mathrm{pg} / \mathrm{mL}$; IL-10, 5 $\mathrm{pg} / \mathrm{mL} ; \mathrm{TNF}-\alpha, 10 \mathrm{pg} / \mathrm{mL} ;$ CXCL8, $3 \mathrm{pg} / \mathrm{mL}$; GM-CSF, 3 $\mathrm{pg} / \mathrm{mL} ;$ and $\mathrm{M}-\mathrm{CSF}, 9 \mathrm{pg} / \mathrm{mL}$.

\section{Quality of life measurements}

We used the Functional Assessment of Chronic Illness Therapy-Biologic Response Modifier (FACT-BRM version 4) to assess changes in patients' quality of life. This questionnaire is a 44-item, cancer-specific measure of healthrelated quality of life[33] It consists of 27 core items that assess physical, social and family, emotional, and functional well-being (FACT-G)[34] and 17 items that assess disease and treatment-related issues specific to patients receiving cytokine therapy (BRM)[35] Higher scores represent better quality of life. Recent research suggests a change of 7 or more on the FACT-G total score indicates a clinically significant change in quality of life[36] Patients completed the 44-item FACT-BRM on days $-8,-4,-1$, and 9 of the first treatment course and on days -1 and 9 of the second and third treatment courses.

\section{Statistics}

Wilcoxon rank sum tests were used to evaluate differences in variables between individual time points. No correction was made for multiple testing. Statistical significance was declared for p-values $<5 \%$. SAS 9.1 was used for statistical analyses.

\section{Results \\ Patient characteristics}

Characteristics of the first 25 enrolled patients and their tumors and prior treatment regimens are summarized in Table 1 . The median age at enrollment into the study was 62 years (range, 49-77 years). Most of the patients had serous EOC that was ovarian in origin.

\section{Hematopoietic effects}

All 25 patients were evaluated for the hematopoietic effects of chemoimmunotherapy. Chemistry analyses were part of ongoing safety evaluations and are not reported here in detail. The white blood cell (WBC) count increased as expected after each GM-CSF cycle and peaked 6 days after the first dose of carboplatin (Figure 2A shows means with $95 \%$ confidence intervals). The neutrophil and eosinophil curves followed that of the WBC. The MO count increased considerably after the first immunotherapy dose of GM-CSF and IFN- $\gamma 1 \mathrm{~b}$ and on day $9 \mathrm{com}$ pared with day -8 (Figure 2B). Prechemotherapy platelet counts were statistically unchanged throughout the 3month study period, although they did increase significantly on day 9 of the second $(P=.002)$ and third $(P \leq$ .04 ) treatment courses (Figure 2C). When we compared the values obtained on day -8 with those obtained on day 

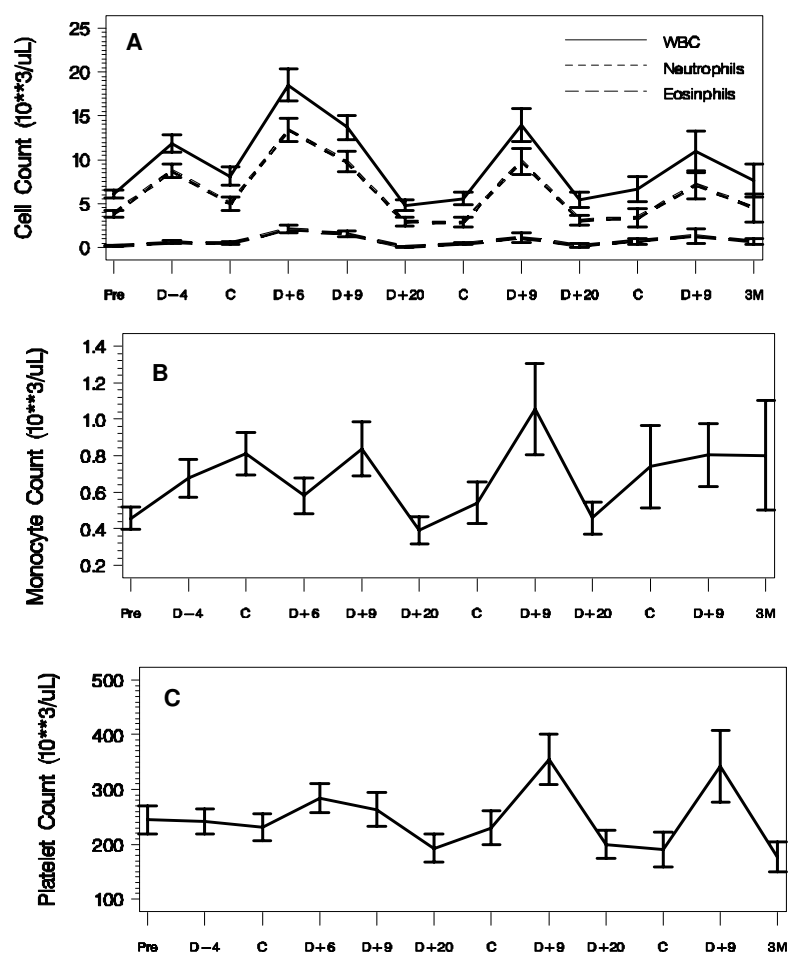

Figure 2

Hematologic Cell Counts as Function of Time in $\mathbf{2 5}$ patients. "Pre" - Study Baseline; "D" - day number preceding first cycle (D-) or following (D+) carboplatin ("C") administration; "3M" - 3 months after initiation of therapy. Values are expressed as means and $95 \%$ Cls.

9, there were significant increases in total WBC, neutrophil, MO, and eosinophil counts at day $9(P \leq .001$ for all comparisons) (Fig. 2A-C).

\section{Adjustments to treatment regimen}

Sixteen of the $25(64 \%)$ patients required a dose escalation of GM-CSF from 400 to $600 \mu \mathrm{g}$. Twenty of the 25 (80\%) patients met the target $\mathrm{MO}$ expansion of a doubling from day -8 and $>1,000$ cells $/ \mu \mathrm{L}$. For two patients, the dose was reduced from 600 to $400 \mu \mathrm{g}$ because of toxicity, one before and one after the second course. In five of the 25 patients $(20 \%)$, the presence of neutropenia or thrombocytopenia required that the day 7 dose of IFN$\gamma 1 \mathrm{~b}$ not be given ( 4 after $2^{\text {nd }}$ and 1 after $3^{\text {rd }}$ course).

\section{Immunologic cell alterations}

For 12 of the 25 patients (48\%), MO and DC subsets from the first treatment course were examined as a function of time (Figure 3A-E). Compared with pretreatment, on day 9 , there were significant increases in the absolute number of activated MOs, i.e, HLA-DR+ cells $(P=.04)$, cells with high-affinity Fc receptor $(\mathrm{FcR})$, i.e, $. \mathrm{CD} 64+$ cells $(P=.01)$, and cells with chemokine receptor, i.e, . CXCR3+ cells $(P \leq$ $.02)$. There were no significant differences in the absolute number of cells with low-affinity FcR (i.e,. CD16+ cells), the absolute number of DCs (i.e, CD11c+ and CD123+ cells), or the proportion of DC subsets. In addition, there were no significant alterations in the numbers or proportions of natural killer (i.e,. CD3-CD56+) cells over the time period under study (data not shown). The proportions of CD83+ DCs and CD2+ cells at day -8 were $1.4 \%$ and $3.7 \%$, respectively.

We also examined the CD32 MO population in a small sample of four patients. On day -8 , the mean $( \pm \mathrm{SD})$ number of CD32+ MO/MAs was $99.4 \pm 0.4$, and the mean fluorescent intensity (MFI) was $145 \pm 51$. On day 9, the mean number of CD32+ MO/MAs remained stable (99.9 \pm 0.2 ) but the mean MFI increased to $250 \pm 45$.

CD32B expression was also measured in a small sample of two patients. The mean expression level was $36 \pm 5 \%$ on day -8 and $37.4 \pm 0.2 \%$ on day 9 , and the corresponding mean MFI values were $16 \pm 1 \%$ and $22 \pm 1.4 \%$.

\section{MO-mediated tumor cell cytotoxicity and ADCC}

Using the SKOV3 cell line and a 20:1 effects-to-target ratio, we found overall lower in vitro $\mathrm{MO}$-mediated tumor cell cytotoxicity and ADCC with purified MOs from EOC patients than with purified MOs from buffy coat samples of normal subjects (Table 2).

Next, we compared the effect of GM-CSF treatment in vitro on MO-mediated tumor cell cytotoxicity and ADCC in samples from days $-4,1$, and 9 of the first treatment course and 3 months after the first treatment course was begun with samples from pretreatment baseline (Table 3). There was no significant effect of trastuzumab treatment overall, although the number of patients tested was small and the standard deviations large. More patients are needed to assess whether GM-CSF treatment enhances the ability of MOs from blood to mediate cytotoxicity or ADCC against the SKOV3 cell line and at later time points as tumor burden decreases in responding patients.

\section{Plasma cytokine levels}

Plasma levels of proinflammatory cytokines and the chemokine CXCL8 are shown in Table 4. During the first treatment course, (up to day 9), there were no statistically significant alterations in CXCL8 levels. M-CSF, also a product of $\mathrm{MO} / \mathrm{MA}$ activation and which can be distinguished from GM-CSF by ELISA, was significantly increased after $\mathrm{MO}$ maturation and activation on $\mathrm{D}$. In contrast, at 3 months, plasma levels of IL- $1 \alpha$, IL- 6 , and IL8 were significantly decreased $(P \leq .033$ for all three comparisons). GM-CSF levels were increased at each post 

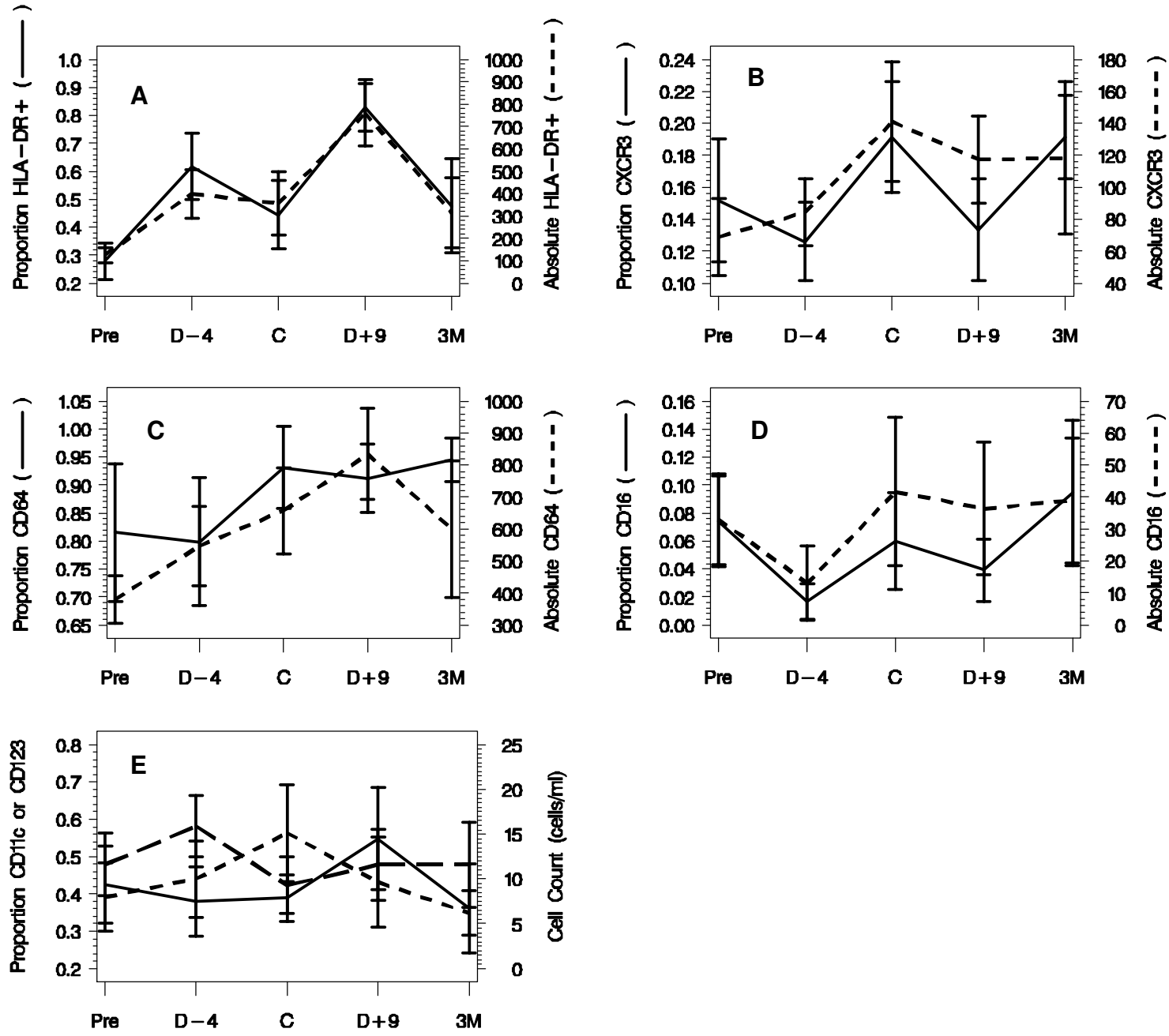

Figure 3

Immunologic cell alterations as a function of time in $\mathbf{I} 2$ patients. Proportions and absolute numbers of activated monocytes (HLA-DR+); low affinity FCR (CDI6+); high affinity FCR (CD64+); chemokine receptor (CXCR3+); DCs (CDI Ic+ and CDI32+). D4- = post GM-CSF dose; D9+ = post GM-CSF plus IFN $\gamma$. Values are expressed as means with $95 \% \mathrm{Cl}$. Note: Solid lines represent proportions and short dashed lines represent total or absolute counts. In Figure E, a long dashed line represents the proportion of CDI23 cells.

treatment time point, suggesting that daily doses of GMCSF were associated with its detection in the circulation.

\section{Preliminary toxicities}

All 25 patients were evaluated for up to 3 months for toxicity. Treatment with the cytokines GM-CSF and IFN- $\gamma 1 \mathrm{~b}$ was well tolerated overall. Consistent with prior reports, 18 patients (72\%) initially experienced grade 3 fatigue. The fatigue did not recur in subsequent treatment courses in any patient. One patient withdrew after the second treatment course because of grade 3 fatigue and chest tightness attributed to GM-CSF treatment. One patient who developed grade 1 liver toxicity after the third treatment course had to be removed from study after the fifth treatment course. A liver biopsy examination suggested drug-induced injury, but a viral etiology could not be excluded since there was serologic evidence of prior cytomegalovirus exposure. Six of the 25 patients required carboplatin desensitization for an allergic reaction in the second or third treatment course. Two patients experienced a severe allergic reaction to carboplatin and were removed from the study after the third and fourth treatment course, respectively. 
Table 2: MO-Mediated and Antibody-Dependent Cellular Cytotoxicity of Untreated MOs from EOC Patients and Normal Subjects

\begin{tabular}{lcccc}
\hline & \multicolumn{2}{c}{ EOC Patients } & \multicolumn{2}{c}{ Normal Donor Samples* } \\
\cline { 2 - 4 } MO antibody treatment & No. & Mean \pm SD & No. & Mean \pm SD \\
\hline None & 8 & $0.8 \pm 1.9$ & 4 & $3.4 \pm 3.2$ \\
2B6 antibody & 6 & $1.0 \pm 2.3$ & 4 & $8.5 \pm 5.0$ \\
trastuzumab & 8 & $2.5 \pm 3.1$ & 5 & $11.5 \pm 11.1$ \\
trastuzumab + 2B6 antibody & 6 & $4.1 \pm 4.4$ & 6 & $9.9 \pm 5.9$ \\
\hline
\end{tabular}

All experiments run with a concurrent control from 3 cryopreserved donor samples (see Methods).

\section{Quality of life}

In the first treatment course, there was no significant change in FACT-G and BRM scores during cytokine administration before the infusion of carboplatin (FACTG: day $-8,89$; day $-4,86$; day $-1,85$; BRM: day $-8,54$; day $-4,53$; day $-1,52)$. On day 9 , there was a statistically and clinically significant decrease in the FACT-G $(90 v 81 ; P=$ $.009)$ and BRM (54 v 49; $P<.02)$ scores compared with day -8 . The day before the start of the second treatment course, the FACT-G scores returned to pretreatment baseline values, but the BRM scores remained significantly suppressed ( $54 v 50 ; P=.03$ ). A similar pattern was seen for the third treatment course. Symptoms specifically related to BRM never returned to pretreatment baseline levels.

\section{Clinical response of patients through three treatment courses}

Ten of the 25 patients (40\%) had a clinical response, as based on measurable disease, after completion of three chemoimmunotherapy courses. Eighteen of these 25 patients $(72 \%)$ had at least a $50 \%$ decline or normalization of the CA-125 level from pretreatment baseline through the end of the third treatment course, confirmed by two post-treatment readings.

\section{Discussion}

As stated earlier, the purpose of this paper is to describe the main hematologic and immunologic effects observed in the initial 25 patients of the ongoing phase II chemotherapy clinical trial. Since the trial is ongoing, reporting of response and toxicity information should be considered preliminary. To facilitate the statistical analysis, we selected only the first 3 courses of treatment.

We have shown that 3 months of a prechemotherapy priming schedule of daily subcutaneous GM-CSF for 7 days followed by a postchemotherapy schedule of subcutaneous GM-CSF for 7 days was reasonably well tolerated. Increased absolute numbers of total WBCs, neutrophils and MOs were observed. GM-CSF is the only approved drug in the United States that can also stimulate non-granulocyte myeloid lineages such as MO/MAs and DCs.

The platelet count after three chemoimmunotherapy courses was not significantly altered from the pretreatment baseline count, but we thought it remarkable that there were statistically significant increases in platelet levels on day 9 of the second and third treatment courses. To our knowledge, ours is the first report of a significantly higher platelet count after GM-CSF treatment than before GM-CSF treatment. This increase occurred at the same time as the counts of the myeloid lineages were increased and the levels of IL-6, which has platelet-stimulating

Table 3: Mean Percentage \pm SD Cytotoxicity during Treatment against the SKOV3 Ovarian Tumor Cell Line

\begin{tabular}{lccccc}
\hline & \multicolumn{5}{c}{ Course I } \\
\cline { 2 - 5 } MO Treatment & Day -8 & Day -4 & Day I & Day 9 & 3 Months* \\
\hline None & $0.8 \pm 1.9(8)^{\dagger}$ & $2.4 \pm 3.6(8)$ & $1.3 \pm 1.4(6)$ & $2.8 \pm 3.4(7)$ & $1.9 \pm 0.9(3)$ \\
2B6 antibody & $1.0 \pm 2.3(6)$ & $2.3 \pm 2.7(6)$ & $4.1 \pm 3.2(4)$ & $4.6 \pm 3.0(5)$ & $4.6 \pm 2.3(3)$ \\
trastuzumab & $2.5 \pm 3.1(8)$ & $3.7 \pm 3.1(8)$ & $5.8 \pm 4.7(8)$ & $4.7 \pm 5.4(7)$ & $4.3 \pm 3.0(3)$ \\
trastuzumab + 2B6 a/b & $4.1 \pm 4.4(6)$ & $5.2 \pm 3.3(6)$ & $10.8 \pm 8.5(6)$ & $7.6 \pm 4.3(6)$ & $8.7 \pm 5.0(3)$ \\
\hline
\end{tabular}

*Three months after first chemoimmunotherapy course was begun. $\dagger(n)=$ number of patients tested at each time period. $P>.05$ for day -8 vs each of the other categories (day -4 , day I, day 9 , or 3 months). 
Table 4: Plasma levels of cytokines and growth factors before and during 3 months of treatment.

\begin{tabular}{|c|c|c|c|c|c|}
\hline Cytokine or Chemokine & Day* & No. of Patients & Mean Concentration (pg/mL) & Change from Day -8 (pg/mL) & $\mathbf{P}_{\text {value }}{ }^{\dagger}$ \\
\hline \multirow[t]{5}{*}{ IL-I $\alpha$} & -8 & 13 & 43 & & \\
\hline & -4 & 12 & 47 & 5.2 & 0.224 \\
\hline & 1 & 13 & 48 & 4.8 & 0.172 \\
\hline & 9 & 13 & 48 & 4.6 & 0.437 \\
\hline & $3 M$ & 11 & 29 & -16.3 & 0.033 \\
\hline \multirow[t]{5}{*}{ IL-I $\beta$} & -8 & 13 & 109 & & \\
\hline & -4 & 12 & 115 & 8.0 & 0.295 \\
\hline & I & 13 & 122 & 13.6 & 0.052 \\
\hline & 9 & 13 & 125 & 16.4 & 0.069 \\
\hline & $3 M$ & 11 & 106 & -6.4 & 0.501 \\
\hline \multirow[t]{5}{*}{ IL-6 } & -8 & 13 & 62 & & \\
\hline & -4 & 12 & 76 & 12.3 & 0.166 \\
\hline & 1 & 13 & 72 & 10.2 & 0.164 \\
\hline & 9 & 13 & 79 & 16.3 & 0.094 \\
\hline & $3 M$ & 11 & 50 & -18.4 & 0.014 \\
\hline \multirow[t]{5}{*}{ IL-8 } & -8 & 13 & 12 & & \\
\hline & -4 & 12 & 15 & 3.0 & 0.074 \\
\hline & I & 13 & 14 & 1.9 & 0.222 \\
\hline & 9 & 13 & 13 & 1.2 & 0.463 \\
\hline & $3 M$ & 11 & 8 & -4.6 & 0.019 \\
\hline \multirow[t]{5}{*}{ IL-10 } & -8 & 13 & 9 & & \\
\hline & -4 & 12 & 14 & 4.1 & 0.130 \\
\hline & 1 & 13 & II & 1.7 & 0.149 \\
\hline & 9 & 13 & 12 & 3.4 & 0.157 \\
\hline & $3 M$ & 11 & 9 & -1.2 & 0.418 \\
\hline \multirow[t]{5}{*}{ TNF- $\alpha$} & -8 & 13 & 150 & & \\
\hline & -4 & 12 & 177 & 26.8 & 0.265 \\
\hline & I & 13 & 174 & 23.4 & 0.200 \\
\hline & 9 & 13 & 152 & 1.6 & 0.937 \\
\hline & $3 M$ & 11 & 121 & -39.8 & 0.377 \\
\hline \multirow[t]{5}{*}{ GM-CSF } & -8 & 13 & 2.9 & & \\
\hline & -4 & 11 & 7.1 & 4.1 & 0.007 \\
\hline & 1 & 13 & 3.5 & 0.6 & 0.012 \\
\hline & 9 & 13 & 11.6 & 8.6 & 0.005 \\
\hline & $3 M$ & 11 & 5.7 & 2.6 & $0.04 I$ \\
\hline \multirow[t]{5}{*}{ M-CSF } & -8 & 13 & 519 & & \\
\hline & -4 & 12 & 505 & -26.0 & 0.847 \\
\hline & 1 & 13 & 610 & 90.8 & 0.153 \\
\hline & 9 & 13 & 863 & 343.9 & 0.007 \\
\hline & $3 M$ & 11 & 558 & 13.6 & 0.902 \\
\hline
\end{tabular}

*Days $-8,-4, I$, and 9 of the first chemoimmunotherapy course; $3 M, 3$ months after the first chemoimmunotherapy course was begun. $\dagger P$ values not adjusted for multiple comparisons.

properties, were decreased. An early study had reported higher platelet levels in a group of patients treated with postchemotherapy GM-CSF than in another patient group not treated with GM-CSF after chemotherapy[37] The frequency of carboplatin hypersensitivity was not higher than prior reports and probably reflects the number of prior carboplatin courses. [38] In contrast, treatment with macrophage colony-stimulating factor and IFN- $\gamma$ has been shown to produce grade 4 thrombocytopenia, grade 3 hepatic toxicity, and exacerbation of chronic obstructive pulmonary disease[39]
In our study, the eosinophil count was increased on day 9 of all three treatment courses, but the count had returned to pretreatment baseline levels 3 months after the chemoimmunotherapy regimen had been started. An earlier study showed no association between the occurrence of hypersensitivity reactions to carboplatin and eosinophilia.[37]

One of the aims of our study was to determine whether priming and postchemotherapy treatment with cytokines GM-CSF and IFN- $\gamma 1 \mathrm{~b}$ increases MO counts. We found that $\mathrm{MO}$ counts increased significantly on day 9 of each of the 
three treatment courses and that $\mathrm{MO}$ values almost doubled from day -8 to day 9 of each treatment course. Eighty percent of the patients met the criteria of a doubling of the $\mathrm{MO}$ count and $>1,000 \mathrm{MOs} / \mu \mathrm{L}$. From our results, daily subcutaneous administration of $400 \mu \mathrm{g}$ of GM-CSF appears to be a reasonable starting dose and schedule in this previously treated patient population. In another study, although daily and twice daily GM-CSF dosing over 10 to 14 days was administered after carboplatin and cyclophosphamide treatment, the addition of a twice daily prechemotherapy priming schedule for 4 days resulted in unacceptable toxicity in a small cohort of patients.[40]

IFN- $\gamma$ is the most potent clinically available activator of $\mathrm{MO} / \mathrm{MAs}$. In adaptive immunity, IFN- $\gamma$ participates in the conversion of precytotoxic to cytotoxic effector T cells. IFN- $\gamma$ also enhances natural cell activity and can inhibit tumor cell proliferation directly by a variety of mechanisms[41] An in vitro study has suggested that IFN- $\gamma$ plus IL-4 can induce maturation of myeloid DCs to a predominantly $\mathrm{CD}_{11 \mathrm{C}^{+}}$phenotype after GM-CSF administration[42] We did not observe statistically significant alterations in DC numbers or maturation. IFN- $\gamma$-activated MDM MOs may contribute to the destruction or inhibition of tumor cells by releasing tumor-inhibitory molecules or by direct surface cell-to-cell interactions, such as ADCC or phagocytosis, using the Fc- $\gamma$ R pathway. Activated $\mathrm{MO} / \mathrm{MAs}$ can produce oxygen radicals and nitric oxide. In an early study, subcutaneous administration of IFN- $\gamma$, even after a single dose of $100 \mu \mathrm{g}$, increased $\mathrm{H}_{2} \mathrm{O}_{2}$ production and Fc- $\gamma$ R expression by MOs, whereas clinical toxicity was low [43] In other studies, intravenous IFN$\gamma$ at doses up to $100 \mu \mathrm{g}$ also induced $\mathrm{MO}$ secretion of $\mathrm{H}_{2} \mathrm{O}_{2}$, [44] although higher doses of IFN- $\gamma(500 \mu \mathrm{g}$ or higher by continuous infusion) were associated with immunosuppressive effects[45] We considered the 100- $\mu \mathrm{g}$ subcutaneous dose appropriate for combination with GM-CSF in the current study. IFN- $\gamma$ has also shown activity against ovarian cancer in preclinical models[46] and in patients receiving intravenous or intraperitoneal injections $[47,48]$ A recently reported randomized trial of cisplatin and cyclophosphamide plus IFN- $\gamma$ (administered subcutaneously at a schedule of $0.1 \mathrm{mg}$ for six doses per chemotherapy course) resulted in increased time to tumor progression among ovarian cancer patients and increased survival compared with cisplatin and cyclophosphamide alone[49] Because of the antiproliferative activity of IFN$\gamma$, dividing cells such as bone marrow progenitors might be susceptible to frequently repeated systemic treatments. Despite our limiting rIFN- $\gamma 1 \mathrm{~b}$ to four doses per treatment course, the dosing had to be reduced to one per GM-CSF cycle in five susceptible patients.
GM-CSF plus rIFN- $\gamma 1 \mathrm{~b}$ also produced alterations in the activation cell surface marker phenotype of the MO population. Compared with pretreatment baseline, the proportion and number of HLA-DR+ cells increased significantly after GM-CSF treatment alone (day -4) or with IFN- $\gamma 1 \mathrm{~b}$ (day 9) (Fig. 3A). The numbers of CD64+ cells (i.e, . cells with high-affinity FcRs) also increased, but there were no significant changes in CD16+ cells (i.e,. cells with low-affinity FcRs). In contrast, the mean fluorescent intensity (MFI) of CD32+ cells, which made up $100 \%$ of MOs before treatment with GM-CSF, increased significantly. Two previous studies had suggested that GM-CSF can stimulate antitumor functions, such as ADCC, or MOmediated cytotoxicity $[17,50]$ We found that after the administration of GM-CSF and rIFN- $\gamma 1 \mathrm{~b}$, there was an increase in the total number of MOs and activated subsets. However, there was no statistically significant enhancement of the MO-mediated cytotoxicity or ADCC effect after treatment. These results might be due to the fact that the CD16 low-affinity FcR is expressed on only about $10 \%$ of MOs and was not significantly altered; however, MOs also express other low-affinity FcRs, including CD32 and its allotypes $\mathrm{CD} 32 \mathrm{~A}$ and $\mathrm{CD} 32 \mathrm{~B}$. CD32A enhances ADCC, whereas binding of CD32B blocks ADCC[51] We have shown that CD32B, the inhibitory low-affinity FcR, is expressed by approximately $30 \%$ of $\mathrm{MO} / \mathrm{MAs}$. The reduced ADCC effect observed prior to the treatment compared to values from normals suggest that these patients might be exhibiting a defect in ADCC. We recently described a similar defective ADCC effect utilizing macrophage-derived monocytes (MDM) from blood and ascites of EOC patients [32], which is in agreement with the current findings. It is possible that the tumor suppressive effects might prevail, at least on certain MO-mediated antitumor activity, when tumor burden and consequently the cytokine suppressor environment is larger. This situation could be predicted to occur at earlier stages of chemotherapy induction or reinduction.

Previous work has demonstrated that systemic administration of GM-CSF increases numbers of intraperitoneal MAs, which could be important in ovarian cancer because EOC is primarily a tumor of the peritoneal cavity[12] In our study, the numbers of CXCR3+ MOs increased significantly on day 9 after administration of GM-CSF and rIFN$\gamma 1 \mathrm{~b}$ (Fig. 3). CXCR3, which is present on activated $\mathrm{MO} /$ MAs and on activated T cells, [52] binds several rIFN- $\gamma 1 \mathrm{~b}-$ induceable chemokines, including CXCL9/Mig, CXCL10/ IP-10, and CXCL11/I-TAC[53] These chemokines might facilitate recruitment of activated leukocyte subsets to the tumor site. IFN- $\gamma$ - inducible chemokines may also induce the proliferation of vascular pericytes that may induce antitumor effects mediated through the common receptor CXCR3. The CXC chemokines are a family of molecules that can also regulate angiogenesis. The ELR+ molecules 
are generally considered pro-angiogenic, while the ELRmolecules are considered angiostatic[54] I-TAC has the highest affinity for CXCR3,[55] and rIFN- $\gamma 1 \mathrm{~b}$ can upregulate the production of Mig, IP-10, and I-TAC[52] Tumorassociated $\mathrm{MO} / \mathrm{MAs}$ have a range of effects that include both pro- and anti-inflammatory responses. Activation of $\mathrm{MO} / \mathrm{MAs}$ by GM-CSF and IFN- $\gamma$ might enhance antitumor activity, but might also secrete products that are proangiogenic or contribute to growth and metastasis[56,57] However, one might speculate that, as tumor burden decreases during chemotherapy, activated $\mathrm{MO} / \mathrm{MA}$ might be polarized more towards antitumor effects as they are released from the influence of the tumor.

Measurements of cytokines can provide some indication of the patient's tumor environment and might also be useful for monitoring immunomodulatory alterations of the treatment. We showed here that there were no significant increases in the plasma levels of the proinflammatory cytokines IL- $1 \alpha$, IL- 6 , CXCL- 8 , or of TNF- $\alpha$, even though these proteins are produced by activated MO/MA. This suggests that the combination of GM-CSF and IFN- $\gamma 1 \mathrm{~b}$ may not directly enhance production of these proangiogenic cytokines in vivo. In contrast, the plasma levels of CXCL8 and IL $1 \alpha$ were significantly decreased at 3 months as a number of patients $(72 \%$ showed a decline in CA125 values) were beginning to show responses.

The preliminary response data for 25 patients showed that 6 experienced a complete response and 4 experienced a partial response. It was previously demonstrated that the length of an initial response to platinum-based chemotherapy in ovarian cancer is predictive of the duration of future responses [58] After completing accrual to the phase II portion of the current trial, we will determine whether this schedule of GM-CSF and IFN- $\gamma 1 \mathrm{~b}$ plus carboplatin enhances progression-free survival over prior courses of treatment.

The quality of life component of the study demonstrated little change in general and BRM-specific symptoms due to the cytokine treatments. However, both aspects of quality of life were significantly affected by carboplatin treatment. General aspects of quality of life returned to pretreatment baseline levels between treatment courses, whereas the BRM-specific symptoms remained suppressed. This difference was most likely due to the residual effects of carboplatin. Understanding the quality of life effects of novel combinations of treatment is critical. Examination of whether the BRM-specific symptoms return to pretreatment baseline levels after treatment is ended will be important to determine.

In conclusion, this novel regimen of GM-CSF, IFN- $\gamma 1 \mathrm{~b}$, and carboplatin has an acceptable toxicity profile and sig- nificantly increases blood levels of activated MOs, platelets, WBCs, and neutrophils. Completion of the phase II study will provide data on response, time to tumor progression in responders compared with prior treatments, and toxicity and will provide an opportunity to determine whether ADCC activity recovers in responding patients.

\section{Acknowledgements}

We gratefully acknowledge the support of Berlex, Bristol-Myers Squibb, and InterMune in the conduct of this study.

\section{References}

I. Jemal A, Murray T, Ward E, Samuels A, Tiwari RC, Ghafoor A, Feuer EJ, Thun MJ: Cancer statistics, 2005. CA Cancer J Clin 2005, 55:10-30.

2. Ries L: SEER Cancer Statistics Review, 1973-1999. NCl: Bethesda, MD 2002.

3. McGuire WP, Hoskins WJ, Brady MF, Kucera PR, Partridge EE, Look KY, Clarke-Pearson DL, Davidson M: Cyclophosphamide and cisplatin compared with paclitaxel and cisplatin in patients with stage III and stage IV ovarian cancer. N Engl J Med 1996, 334: $1-6$.

4. Ozols RF, Bundy BN, Fowler J: Randomized phase III study of cisplatin/paclitaxel versus carboplatin/paclitaxel in optimal stage III epithelial ovarian cancer: A Gynecologic Oncology Group trial (GOG I 58). Proc Am Soc Clin Oncol 1999, I 8:A I373.

5. Gore $M$ : Treatment of relapsed epithelial ovarian cancer. 2001:468-476.

6. Eisenhauer EA, Vermorken JB, van Glabbeke M: Predictors of response to subsequent chemotherapy in platinum pretreated ovarian cancer: a multivariate analysis of 704 patients [seecomments]. Ann Oncol 1997, 8:963-968.

7. Parmar MK, Ledermann JA, Colombo N, du Bois A, Delaloye JF, Kristensen GB, Wheeler S, Swart AM, Qian W, Torri V, Floriani I, Jayson G, Lamont A, Trope C: Paclitaxel plus platinum-based chemotherapy versus conventional platinum-based chemotherapy in women with relapsed ovarian cancer: the ICON4/AGOOVAR-2.2 trial. Lancet 2003, 36 I:2099-2106.

8. Melichar B, Freedman RS: Immunology of the peritoneal cavity: relevance for host-tumor relation. Int J Gynecol Cancer 2002, I 2:3-17.

9. Bernasconi S, Matteucci C, Sironi M, Conni M, Colotta F, Mosca M, Colombo N, Bonazzi C, Landoni F, Corbetta G: Effects of granulocyte-monocyte colony-stimulating factor (GM-CSF) on expression of adhesion molecules and production of cytokines in blood monocytes and ovarian cancer-associated macrophages. Int J Cancer 1995, 60:300-307.

10. Triozzi PL, Tucker F, Benzies T, Balcerzak SP: Antitumor and accessory immune activities of peripheral blood stem cells mobilized with granulocyte-macrophage colony-stimulating factor. Bone Marrow Transplant 1996, 18:47-52.

II. Allavena P, Peccatori F, Maggioni D, Erroi A, Sironi M, Colombo N, Lissoni A, Galazka A, Meiers W, Mangioni C: Intraperitoneal recombinant gamma-interferon in patients with recurrent ascitic ovarian carcinoma: modulation of cytotoxicity and cytokine production in tumor-associated effectors and of major histocompatibility antigen expression on tumor cells. Cancer Res 1990, 50:7318-7323.

12. Metcalf $D$, Nicola NA: Actions of the colony-stimulating factors in vivo. In The hemopoietic colony-stimulating factors: from biology to clinical applications New York, Cambridge University Press; 1995: 188-204.

13. Vadhan-Raj S, Broxmeyer HE, Hittelman WN, Papadopoulos NE, Chawla SP, Fenoglio C, Cooper S, Buescher ES, Frenck RWJ, Holian $A$ : Abrogating chemotherapy-induced myelosuppression by recombinant granulocyte-macrophage colony-stimulating factor in patients with sarcoma: protection at the progenitor cell level. J Clin Oncol 1992, I0:1266-1277.

14. Vadhan-Raj S, Broxmeyer HE, Hittelman WN, Papadopoulos NE, Chawla SP, Fenoglio C, Cooper S, Buescher ES, Frenck RWJ, Holian A, Perkins RC, Scheule RK, Gutterman JU, Salem P, Benjamin RS: Abrogating chemotherapy-induced myelosuppression by 
recombinant granulocyte-macrophage colony-stimulating factor in patients with sarcoma: Protection at the progenitor cell level. Classic Papers and Current Comments 2002, 7:848-860

15. Spitler LE, Grossbard ML, Ernstoff MS, Silver G, Jacobs M, Hayes FA, Soong SJ: Adjuvant therapy of stage III and IV malignant melanoma using granulocyte-macrophage colony-stimulating factor. J Clin Oncol 2000, 18:1614-1621.

16. Cortes J, Kantarjian H, O'Brien S, Kurzrock R, Keating M, Talpaz M: GM-CSF can improve the cytogenetic response obtained with interferon-alpha therapy in patients with chronic myelogenous leukemia. Leukemia 1998, I 2:860-864.

17. Grabstein KH, Urdal DL, Tushinski RJ, Mochizuki DY, Price VL, Cantrell MA, Gillis S, Conlon PJ: Induction of macrophage tumoricidal activity by granulocyte-macrophage colony-stimulating factor. Science 1986, 232:506-508.

18. Arellano M, Waller EK: Granulocyte-macrophage-colony-stimulating factor and other cytokines: as adjuncts to cancer immunotherapy, stem cell transplantation, and vaccines. Curr Hematol Rep 2004, 3:424-43I.

19. Basak SK, Harui A, Stolina M, Sharma S, Mitani K, Dubinett SM, Roth MD: Increased dendritic cell number and function following continuous in vivo infusion of granulocyte macrophage-colony-stimulating factor and interleukin-4. Blood 2002, 99:2869-2879.

20. Armitage JO: Emerging applications of recombinant human granulocyte-macrophage colony-stimulating factor. Blood |998, 92:449|-4508.

21. Buter J, Pinedo HM: Neoadjuvant chemoimmunotherapy in locally advanced breast cancer: a new avenue to be explored. Curr Oncol Rep 2003, 5: 17I-176.

22. de Gast GC, Klumpen HJ, Vyth-Dreese FA, Kersten MJ, Verra NC, Sein J, Batchelor D, Nooijen WJ, Schornagel JH: Phase I trial of combined immunotherapy with subcutaneous granulocyte macrophage colony-stimulating factor, low-dose interleukin 2 , and interferon alpha in progressive metastatic melanoma and renal cell carcinoma. Clin Cancer Res 2000, 6: | 267-| 272.

23. Ryan CW, Vogelzang NJ, Dumas MC, Kuzel T, Stadler WM: Granulocyte-macrophage-colony stimulating factor in combination immunotherapy for patients with metastatic renal cell carcinoma: results of two phase II clinical trials. Cancer 2000, 88:1317-1324.

24. Therasse P, Arbuck SG, Eisenhauer EA, Wanders J, Kaplan RS, Rubinstein L, Verweij J, Van Glabbeke M, van Oosterom T, Christian MC, Gwyther SG: New Guidelines to Evaluate the Response to Treatment in Solid Tumors. I Natl Cancer Inst 2000, 92:205-216.

25. Kouwenhoven M, Ozenci V, Teleshova N, Hussein Y, Huang YM, Eusebio A, Link H: Enzyme-linked immunospot assays provide a sensitive tool for detection of cytokine secretion by monocytes. Clin Diagn Lab Immunol 200I, 8: I248-1257.

26. Melichar B, Savary C, Kudelka AP, Verschraegen C, Kavanagh J], Edwards CL, Platsoucas CD, Freedman RS: Lineage-negative human leukocyte antigen-DR+ cells with the phenotype of undifferentiated dendritic cells in patients with carcinoma of the abdomen and pelvis. Clin Cancer Res 1998, 4:799-809.

27. Liu YJ: Dendritic cell subsets and lineages, and their functions in innate and adaptive immunity. Cell 200I, 106:259-262.

28. Sanchez-Torres C, Garcia-Romo GS, Cornejo-Cortes MA, RivasCarvalho A, Sanchez-Schmitz G: CD I6+ and CD I6- human blood monocyte subsets differentiate in vitro to dendritic cells with different abilities to stimulate CD4+ T cells. Int Immunol 200I, | 3:157|-|58|.

29. Crawford K, Gabuzda D, Pantazopoulos V, Xu J, Clement C, Reinherz E, Alper CA: Circulating CD2+ monocytes are dendritic cells. J Immunol 1999, 163:5920-5928.

30. Gordon I, Freedman RS: Monocytes and Macrophages in epithelial ovarian cancer are deficient FcgR mediated functions. Proc of AACR 2005, 46:.

31. Melichar B, Savary CA, Patenia R, Templin S, Melicharova K, Freedman RS: Phenotype and antitumor activity of ascitic fluid monocytes in patients with ovarian carcinoma. Int J Gynecol Cancer 2003, 13:435-443.

32. Gordon IO, Freedman RS: Defective antitumor function of monocyte-derived macrophages from epithelial ovarian cancer patients. Clin Cancer Res 2006, 12:1515-1524.

33. Cella D: Manual of the Functional Assessment of Chronci IIIness Therapy (FACIT) Scales, Center on Outcomes,
Research and Education (CORE). , Evanston Northwestern Healthcare and Northwestern University; 1997.

34. Cella D, Tulsky D, Gray G, Sarafian B, Linn E, Bonomi A, Silberman M, Yellen SB, Winicour P, Brannon J: The functional assessment of cancer therapy scale: development and validation of the general measure. Journal of Clinical Oncology 1993, I I:570-579.

35. Motzer RJ, Murphy BA, Bacik J, Schwartz LH, Nanus DM, Mariani T, Loehrer P, Wilding G, Fairclough DL, Cella D, Mazumdar M: Phase III trial of interferon alpha-2a with or without I3-cis-retinoic acid for patients with advanced renal cell carcinoma. J Clin Oncol 2000, 18:2972-2980.

36. Cella D, Zagari MJ, Vandoros C, Gagnon D, Hurtz HJ, Nortier J: Epoetin alpha treatament results in clinically significant improvements in quality of life in anemic cancer patients when referenced to the general population. J Clin Oncol 2003, 2:366-373.

37. de Vries EG, Biesma B, Willemse PH, Mulder NH, Stern AC, Aalders JG, Vellenga E: A double-blind placebo-controlled study with granulocyte-macrophage colony-stimulating factor during chemotherapy for ovarian carcinoma. Cancer Res 1991, 5I:116-122

38. Zanotti KM, Rybicki LA, Kennedy AW, Belinson JL, Webster KD, Kulp B, Peterson G, Markman M: Carboplatin skin testing: a skintesting protocol for predicting hypersensitivity to carboplatin chemotherapy. J Clin Oncol 200I, 19:3126-3129.

39. Weiner LM, Li W, Holmes M, Catalano RB, Dovnarsky M, Padavic K, Alpaugh RK: Phase I trial of recombinant macrophage colonystimulating factor and recombinant gamma-interferon: toxicity, monocytosis, and clinical effects. Cancer Res 1994, 54:4084-4090.

40. Edmonson JH, Hartmann LC, Long HJ, Colon-Otero G, Fitch TR, Jefferies JA, Braich TA, Maples WJ: Granulocyte-macrophage colony-stimulating factor. Preliminary observations on the influences of dose, schedule, and route of administration in patients receiving cyclophosphamide and carboplatin. Cancer 1992, 70:2529-2539.

4I. Melichar B, Hu W, Patenia R, Melicharova K, Gallardo ST, Freedman RS: rIFNgamma-mediated growth suppression of platinumsensitive and -resistant ovarian tumor cell lines not dependent upon arginase inhibition. J Translational Med 2003, I:.

42. Ito T, Amakawa R, Inaba M, Ikehara S, Inaba K, Fukuhara S: Differential regulation of human blood dendritic cell subsets by IFNs. J Immunol 200I, 166:296I-2969.

43. Maluish AE, Urba WJ, Longo DL, Overton WR, Coggin D, Crisp ER, Williams R, Sherwin SA, Gordon K, Steis RG: The determination of an immunologically active dose of interferon-gamma in patients with melanoma. J Clin Oncol 1988, 6:434-445.

44. Nathan CF, Horowitz CR, de la Harpe J, Vadhan-Raj S, Sherwin SA, Oettgen HF, Krown SE: Administration of recombinant interferon gamma to cancer patients enhances monocyte secretion of hydrogen peroxide. Proc Natl Acad Sci U S A 1985, 82:8686-8690.

45. Kleinerman ES, Kurzrock R, Wyatt D, Quesada JR, Gutterman JU, Fidler IJ: Activation or suppression of the tumoricidal properties of monocytes from cancer patients following treatment with human recombinant gamma-interferon. Cancer Res 1986, 46:540I-5405.

46. Malik ST, Knowles RG, East N, Lando D, Stamp G, Balkwill FR: Antitumor activity of gamma-interferon in ascitic and solid tumor models of human ovarian cancer. Cancer Res 1991, 5 I:6643-6649.

47. Welander CE: Interferon in the treatment of ovarian cancer. Semin Oncol 1988, 15:26-29.

48. Pujade-Lauraine $E$, Guastalla JP, Colombo N, Devillier $P$, Francois $E$, Fumoleau P, Monnier A, Nooy M, Mignot L, Bugat R, Marques C, Mousseau M, Netter G, Maloisel F, Larbaoui S, Brandely M: Intraperitoneal recombinant interferon gamma in ovarian cancer patients with residual disease at second-look laparotomy. J Clin Oncol 1996, 14:343-350.

49. Windbichler $\mathrm{GH}$, Hausmaninger $\mathrm{H}$, Stummvoll $\mathrm{W}$, Graf $\mathrm{AH}$, Kainz $\mathrm{C}$, Lahodny J, Denison U, Muller-Holzner E, Marth C: Interferongamma in the first-line therapy of ovarian cancer: a randomized phase III trial. Br J Cancer 2000, 82: I 38-I I 44

50. Wing EJ, Magee DM, Whiteside TL, Kaplan SS, Shadduck RK: Recombinant human granulocyte/macrophage colony-stimulating factor enhances monocyte cytotoxicity and secretion of 
tumor necrosis factor alpha and interferon in cancer patients. Blood 1989, 73:643-646.

5I. Clynes RA, Towers TL, Presta LG, Ravetch JV: Inhibitory Fc receptors modulate in vivo cytoxicity against tumor targets. Nat Med 2000, 6:443-446.

52. Oppenheim J, Fujiwara $\mathrm{H}$ : The role of cytokines in cancer. Cytokine Growth Factor Rev 1996, 7:279-288.

53. Lazzeri E, Romagnani P: CXCR3-binding chemokines: novel multifunctional therapeutic targets. Curr Drug Targets Immune Endocr Metabol Disord 2005, 5: 109-I I8.

54. Moore BB, Arenberg DA, Addison CL, Keane MP, Polverini PJ, Strieter RM: CXC chemokines mechanism of action in regulating tumor angiogenesis. Angiogenesis 1998, 2:123-134.

55. Cole KE, Strick CA, Paradis TJ, Ogborne KT, Loetscher M, Gladue RP, Lin W, Boyd JG, Moser B, Wood DE, Sahagan BG, Neote K: Interferon-inducible T cell alpha chemoattractant (I-TAC): a novel non-ELR CXC chemokine with potent activity on activated $T$ cells through selective high affinity binding to CXCR3. J Exp Med 1998, 187:2009-2021.

56. Mantovani A, Sozzani S, Locati M, Allavena P, Sica A: Macrophage polarization: tumor-associated macrophages as a paradigm for polarized M2 mononuclear phagocytes. Trends Immunol 2002, 23:549-555.

57. Bingle L, Brown NJ, Lewis CE: The role of tumour-associated macrophages in tumour progression: implications for new anticancer therapies. J Pathol 2002, 196:254-265.

58. Markman M, Markman J, Webster K, Zanotti K, Kulp B, Peterson G, Belinson J: Duration of response to second-line, platinumbased chemotherapy for ovarian cancer: implications for patient management and clinical trial design. J Clin Oncol 2004, 22:3|20-3|25

Publish with Bio Med Central and every scientist can read your work free of charge

"BioMed Central will be the most significant development for disseminating the results of biomedical research in our lifetime. "

Sir Paul Nurse, Cancer Research UK

Your research papers will be:

- available free of charge to the entire biomedical community

- peer reviewed and published immediately upon acceptance

- cited in PubMed and archived on PubMed Central

- yours - you keep the copyright

Submit your manuscript here:

http://www.biomedcentral.com/info/publishing_adv.asp
BiolMedcentral 